\title{
PROFESSORES DO ATENDIMENTO EDUCACIONAL ESPECIALIZADO E \\ DE SALA DE AULA REGULAR: articulações e avaliações sobre o ensino e aprendizagem de alunos incluídos
}

\author{
Daiane Pinheiro 106 \\ Sabrina Maiara de Sousa Duarte 107
}

\begin{abstract}
RESUMO
O trabalho aborda o tema da educação inclusiva dando direcionamentos específicos de estudos às articulações entre professores do atendimento educacional especializado e professores de sala de aula regular. Aproximamos-nos da abordagem teórica dos Estudos Culturais em Educação, tornando possível entender que os sujeitos da educação especial são produzidos no contexto escolar e, portanto, nos espaços estudados assumem identidades de uma anormalidade evidenciada. Segundo experiências acadêmicas de estágio e atividades de pesquisa, observamos que muitos pressupostos políticos não estão sendo de fato efetivados nos contextos de ensino em que atuamos. A partir desses direcionamentos teóricos e políticos, o objetivo desse trabalho é conhecer as relações profissionais pedagógicas do professor de atendimento Educacional Especializado e do professor da sala de aula regular apontando possíveis efeitos na educação dos sujeitos público-alvo da inclusão educacional. O contexto da pesquisa se restringe a duas escolas municipais da cidade de Santarém-PA. Realizamos um levantamento dos instrumentos de planejamento e avaliação utilizados pelos professores com os alunos que apresentam Necessidades Educacionais Especiais. A partir desses dados inferimos análises que nos levaram a entender que a inclusão educacional ainda ancora discursos na incapacidade do sujeito, o que reflete diretamente nas ações e representações profissionais que circulam na escola. E assim, a própria referência à oferta de uma educação especializada passa a causar o estranhamento na escola, ou ainda, o carimbo que marca o sujeito com necessidades educacionais especiais.
\end{abstract}

Palavras-chave: Inclusão Educacional. Educação Especial. Avaliação.

\footnotetext{
106 Mestre em Educação e Mestre em Extensão Rural pela Universidade Federal de Santa Maria. Docente da Universidade Federal do Oeste do Pará. E-mail: daianepinheiroufopa@gmail.com

107 Graduada em Pedagogia pela Universidade Federal do Oeste do Pará. E-mail: brinasousa7@gmail.com
} 


\title{
TEACHERS OF THE SPECIAL EDUCATIONAL SERVICE AND REGULAR CLASSROOM
}

\section{SETTING: links and assessments on included students teaching and learnings}

\begin{abstract}
This work addresses inclusive education giving specific directions on the study of the links between teachers of the special educational services and regular classroom teachers. We address the theoretical approach of Cultural Studies in Education, making it possible to understand that the subject of special education is produced in the school context and therefore the environment studied assumes identities of a demonstrated abnormality. According to academic experiences of teacher training and research activities, we observed that many policy assumptions are not actually being implemented in educational contexts in which we operate. From these theoretical and policy directions, the objective of this work is to know the pedagogical professional relations between the Educational Specialized teacher and the regular teacher in the classroom, pointing at possible effects on the subjects of the educational inclusion. The research context is restricted to two municipal schools in Santarém-PA. We conducted a survey of planning and evaluation tools used by teachers with students who have special educational needs. From these data we infer analysis that led us to understand that educational inclusion still sustain speeches on the subject of disability, which is directly reflected in the actions and professional representations circulating in the school. This way, the very reference to the offer of a specialized education is causing the weirdness in school, or the stamp that marks the special need individual.
\end{abstract}

Keywords: Educational Inclusion. Special Education. Evaluation.

\section{INTRODUÇÃO}

Este trabalho aborda o tema da educação inclusiva, dando direcionamentos específicos de estudo às articulações profissionais entre professores do atendimento educacional especializado (AEE) e professores de sala de aula regular. Tal artigo é fruto de uma pesquisa desenvolvida ao longo do ano de 2015 como requisito para aprovação na disciplina de Trabalho de Conclusão de Curso do curso de Pedagogia da Universidade Federal do Oeste do Pará (Ufopa).

Com base em estudos desenvolvidos no contexto do Grupo de Pesquisa em Educação Especial e Processos Inclusivos (Gpeepi/Cnpq) vinculado à Ufopa, foi possível fazer um aprofundamento conceitual e político sobre a educação especial e inclusiva no cenário educacional. 
Conforme o decreto 7.611 (2011, Art. $3^{\circ}$. III) um dos objetivos do Atendimento Educacional Especializado é "fomentar o desenvolvimento de recursos didáticos e pedagógicos que eliminem as barreiras no processo de ensino e aprendizagem". Ainda sob outras orientações oficiais esse atendimento é citado na Política Nacional de Educação Especial na Perspectiva da Educação Inclusiva (BRASIL/MEC/SEESP, 2008, p. 19).

O AEE é organizado para apoiar o desenvolvimento dos alunos, constituindo oferta obrigatória dos sistemas de ensino e deve ser realizado no turno inverso ao da classe comum, na própria escola ou centro especializado que realize esse serviço educacional.

Para que esse sistema funcione orienta-se que o professor da Educação Especial, atuante no Atendimento Educacional Especializado, estabeleça uma relação de trabalho próxima ao professor de sala de aula regular.

A partir desses direcionamentos teóricos e políticos, propomos problematizar nesse trabalho os efeitos das relações profissionais pedagógicas do professor de AEE e o professor da sala de aula regular na educação dos sujeitos público-alvo da inclusão educacional. O contexto da pesquisa restringe-se a duas escolas municipais da cidade de Santarém-PA. Para analisarmos os efeitos dessas relações na produção e/ou invenção dos sujeitos da educação especial tomando como referência um parecer pedagógico elaborado por um professor de AEE sobre um aluno incluído. Ainda foram feitas entrevistas com docentes envolvidos no processo inclusivo, buscando questionar quanto às relações profissionais estabelecidas nesse contexto. Para tanto buscamos fazer um estudo político e legal sobre as funções e atuações desses profissionais no sistema educacional inclusivo nacional. A importância de discutir esse problema é entender que a responsabilidade da educação dos alunos com NEE não é somente do professor de AEE, mas de toda uma estrutura de gestão educacional.

Os direcionamentos desse estudo estão permeando o campo da avaliação educacional como um dispositivo que permite analisar as 
relações entre os profissionais envolvidos no sistema inclusivo. Isso porque, a avaliação dos sujeitos com NEE deve ser um trabalho em conjunto, que garanta o uso de instrumentos e estratégias pensadas e planejadas por esses profissionais. Pensar a avaliação nessa pesquisa vai além das instâncias escolares. Entendemos a avaliação como um dispositivo da norma social que usa de estratégias de regulação, punição e valorização para colocar em funcionamento a existência de padrões a serem seguidos e atingidos (FROHLICH \& SILVA, 2011).

Para ressignificar o conceito de inclusão, propomos nesse trabalho novas representações, pautadas no poder discursivo e nas relações estabelecidas no contexto escolar. Lopes e Veiga-Neto (2011, p. 129) alerta para isso quando analisar que a escola banaliza ou idealiza o conceito de inclusão,

O uso alargado da palavra inclusão, além de banalizar o conceito e o sentido ético que pode ser dado a ela, também reduz o princípio universal das condições de igualdade para todos a uma simples introdução "de todos" num mesmo espaço físico.

Essas concepções estão ancoradas na abordagem teórica dos Estudos Culturais em educação, tornando possível entender que os sujeitos da educação especial são produzidos nesses espaços e, portanto, assumem identidades de uma anormalidade evidenciada. Identidades essas produzidas pelos próprios professores de sala de aula regular e/Ou do AEE.

Nessa mesma lógica operamos com o conceito de representação que circula entre os professores do AEE e os professores da sala regular. Tal conceito define os meios dessas relações e estabelece os vínculos a serem instituídos, pois a identidade para Hall (2006, p. 38) "[...] permanece sempre incompleta, está sempre "em processo", sempre "sendo formada". E sob esses pressupostos teóricos apresentamos essa pesquisa como um processo 
de construção contínua de novos sujeitos, novas identidades e, portanto, novas verdades ${ }^{108}$.

\section{RELEITURAS POLÍTICAS LEGAIS E HISTÓRICAS DO PANORAMA EDUCACIONAL INCLUSIVO NO BRASIL}

Atualmente no Brasil, dispositivos legais vêm garantindo a inclusão de alunos com necessidades educacionais especiais definindo o público-alvo da Educação Especial, sendo: pessoas com deficiência, transtornos globais do desenvolvimento e com altas habilidades/ superdotação (BRASIL/MEC/SEESP/PNEEPEI, 2008). Esse e outros documentos legais estão ancorados em diversos documentos oficiais de cunho internacional e nacional como: a declaração de direitos humanos de 1948, a Constituição Federal de 1988, a Declaração de Jontien, 1990, a declaração de Salamanca (1994). Esses marcos políticos/legais tem significativa evolução ao longo do tempo com a promoção da garantia de todos à educação. No entanto, a educação das pessoas com deficiência ou alguma necessidade educacional especial esteve registrada por um longo tempo no paradigma da institucionalização.

As pessoas com deficiência começaram a ter um atendimento institucionalizado no período do Império com a criação do Imperial Instituto dos Meninos Cegos em 1854, e posterior, o Instituto dos Surdos Mudos em 1857. Em 1926 foi criada uma instituição para atender pessoas com deficiência mental conhecida pelo Instituto Pestalozzi. Mais tarde foi fundada a primeira Associação de Pais e Amigos dos Excepcionais, no ano de 1954 (MAZZOTTA, 2002).

108 Produzir novas verdades pode ser entendido nos jogos de poder/saber como uma vontade de novos significados, ou seja, a invenção de novos conceitos sobre as coisas e/ou pessoas, negando ou excluindo outras verdades já consolidadas (GALLO \& VEIGA-NETO, 2007). 
Esses marcos históricos forma importantes para a evolução da educação especializada no Brasil, dando direcionamentos posteriores a organização da educação inclusiva.

A educação especial é um componente fundamental para colocar em funcionamento a educação inclusiva a qual é um sistema de ensino que abrange toda uma gestão no setor educacional e escolar. Ou seja, inclusão não depende só da educação especial, depende do funcionamento de todo um sistema. Rech (2011, p.29) comenta sobre o movimento pela inclusão escolar, destacando a Conferência Mundial de Educação Especial que ocorrev em Salamanca em 1994

(...) visa à educação para todos e ao direito à educação em classe regular, difundiu-se por diversos países, incluindo o Brasil na lista de interessados. Isso fez com que o tema da inclusão escolar se tornasse ainda mais emergente.

A década de 1990 marcou o andamento da educação inclusiva no Brasil, e assumiu a educação especial como aliada para efetivação desse processo (BRASIL/LDBN, 1996) (BRASIL/PNEE, 1994). Mais tarde, essa modalidade passa a ser definida como

[...] uma modalidade de ensino que perpassa todos os níveis, etapas e modalidades, realiza o atendimento educacional especializado, disponibiliza os serviços e recursos próprios desse atendimento e orienta os alunos e seus professores quanto a sua utilização nas turmas comuns do ensino regular (BRASIL/PNEEPEI, 2008, p.16).

Esse serviço passa a ser priorizado na rede regular de ensino, tendo apoio especializado para que os obstáculos sejam minimizados. O decreto $n^{\circ} 7.611$ (2011, art. $2^{\circ}$ ) dispõe sobre 0 atendimento educacional especializado (AEE) que deve ser "[...] compreendido como o conjunto de atividades, recursos de acessibilidade e pedagógicos organizados institucional e continuamente". É um complemento e/ou suplemente educacional que deverá ser feito com o público alvo da educação especial sendo as atividades realizadas nas salas de recursos multifuncionais no contra turno da aula regular. O AEE não é um reforço, ele deve enriquecer a 
habilidade cognitiva do educando, e um dos seus objetivos principais é "prover condições de acesso, participação e aprendizagem no ensino regular e garantir serviços de apoio especializados de acordo com as necessidades individuais dos estudantes" (BRASIL/ DECRETO no 7.611, 2011, Art. $3^{\circ}$, I).

Para que o processo inclusivo possa ser desenvolvido de forma qualitativa é preciso que ocorra uma relação profissional pedagógica entre o professor de sala de aula regular e o professor do AEE, em que a função do docente de sala de aula regular diante a inclusão é acionar o professor da Educação Especial, quando achar necessário. O professor do AEE, além das atividades desenvolvidas na sala de recursos multifuncionais, assume a função de formação e orientação dos demais profissionais da escola inclusiva.

Fabris (2011) comenta que muitas escolas tem atribuído a responsabilidade pela inclusão somente ao docente da educação especial, considerando-o salvacionista de todo um sistema. Essas representações implicam no fracasso da inclusão, pois entende o sistema de forma deslocada das outras funções. Assim, a educação especial quando desmembrada da própria escola, impede que essa engrenagem possa funcionar. No entanto Fabris (2011, p.34) questiona: "Como estar preparado desde a formação inicial para assumir o trabalho pedagógico com alunos com deficiência?".

A educação especial passou por vários desafios até que chegasse a ser reconhecida pela sociedade e pelos documentos legais como uma área de saber e modalidade de ensino. A questão não é somente incluir esses alunos para contabilizar dados nas pesquisas e mostrar que no país a inclusão está ocorrendo, que as matrículas estão sendo feitas. É necessário que os professores que trabalham com esses alunos sejam capacitados e que o entendimento sobre os papéis assumidos na escola estejam definidos. 


\section{AÇÕES DOCENTES SOBRE O PROCESSO EDUCACIONAL INCLUSIVO}

Para realizar a prática investigativa desse trabalho foram estabelecidos contatos prévios com duas escolas municipais de SantarémPA e 4 professores que atuam em salas de aulas regulares e no Atendimento Educacional Especializado. Preocupamo-nos em não revelar a identidade das instituições envolvidas e nem dos professores que colaboraram com essa investigação. Desse modo atribuímos as seguintes nomenclaturas: escolas E1 e E2, Professor 1 de sala de aula regular atuante na escola 1 (P1.Regular/E1), Professor 1 de sala de aula regular atuante na escola 2 (P1.Regular/E2), professor 1 de atendimento educacional especializado da escola 1 (P1.AEE) E1) e professor 2 de atendimento educacional especializado da escola 2 (P2.AEE/E2). Ainda foi possível ter acesso a um parecer pedagógico elaborado pela (P1.AEE/E1).

O decreto $n^{0} 7.611$ de 2011, a Política Nacional de Educação Especial na Perspectiva da Educação Inclusiva de 2008 e as Diretrizes Nacionais para Educação Especial na Educação Básica de 2002 orientam para o trabalho em conjunto entre os professores do ensino regular e professores da Educação Especial que atuam no Atendimento Educacional Especializado. Nesse sentido as escolas pesquisadas têm demonstrado seguir orientações legais afirmando que a relação é "muito boa, porque quando sinto dificuldade em como trabalhar com aquele aluno em sala de aula, os professores da sala de Educação Especial orientam [...]" (P1.Regular/E2).

Alguns impasses foram relatados. A professora P1.Regular/E1 afirma que estabelecer essas relações com o professor do AEE "é um pouco complicado porque a professora vem apenas três dias na semana". É importante destacar que segundo orientações legais, o professor de atendimento educacional especializado não deve permanecer na sala de aula regular durante o horário de aula, a não ser quando solicitado pelo professor de sala de aula regular: "As atividades desenvolvidas no atendimento educacional especializado diferenciam-se daquelas realizadas 
na sala de aula comum, não sendo substitutivas à escolarização" (BRASIL/DECRETO n 7.611, 2011, art.50).

Ainda, mesmo que o professor de AEE atue em determinada instituição, muitas vezes deve prestar atendimento itinerante em outras escolas. Essa sobrecarga de trabalho gera o desconforto docente e interfere diretamente na qualidade do trabalho desenvolvido. É importante também destacar que os professores de sala de aula regular devem compreender a função desse profissional na escola, o que muitas vezes é confundido como o salvacionismo do sistema inclusivo. As Diretrizes Nacionais para Educação Especial na Educação Básica (BRASIL, 2001, p.32) considera professores da educação especial aqueles que

[...] desenvolveram competências para identificar as necessidades educacionais especiais, definir e implementar respostas educativas a essas necessidades, apoiar o professor de sala de aula regular, atuar nos processos de desenvolvimento e aprendizagem dos alunos, desenvolvendo estratégias de flexibilização, adaptação curricular e práticas pedagógicas alternativas [...].

A inclusão é um desafio da educação no Brasil, muitas são as dúvidas para que esse processo de inclusão ocorra nas escolas públicas. Ainda há um desentendimento dos papéis exercidos no contexto escolar, isso se torna evidente na fala da professora P1.Regular/El o qual comenta que "com a professora do AEE, eu peço sugestões para desenvolver as atividades com os alunos especiais os quais estão inclusos na classe em que trabalho". Porém, ao ser questionada sobre a frequência das relações profissionais pedagógicas para discutir estratégias didáticas com a professora do AEE, aponta que isso é feito eventualmente ao ano. Reforçamos que as relações entre professores AEE e da sala de aula regular devem ser um processo contínuo de planejamento e de avaliação para produção do parecer pedagógico.

Em contrapartida a professora P1.Regular/E2 afirma que os encontros com a docente do AEE são feitos "diariamente quando necessito de orientações". Essas relações reforçam o entendimento de uma política 
inclusiva funcional. Isso também converge com a formação do educador do AEE. Contudo, esses dados divergem da indicação formativa dada pelo professor AEE da escola E2 o qual não possui formação continuada na área da educação especial e/ou inclusiva. Já o docente 2 do AEE da escola El possui especialização na área, mas se encontra eventualmente ao ano com a professora de sala de aula regular. No que diz respeito sobre a formação do professor da educação especial, este deve ter uma licenciatura e formação especifica na área, possibilitando

\begin{abstract}
A sua atuação no atendimento educacional especializado e deve aprofundar o caráter interativo e interdisciplinar da atuação nas salas comuns do ensino regular, nas salas de recursos, nos centros de atendimento educacional especializado, nos núcleos de acessibilidade das instituições de educação superior, nas classes hospitalares e nos ambientes domiciliares, para a oferta dos serviços e recursos de educação especial. (BRASIL/ PNEEPEI, 2008, p. 19).
\end{abstract}

As diretrizes nacionais para a educação especial na educação básica de 2002 destacam que é necessário no procedimento educativo ser feita uma avaliação pedagógica dos alunos com NEE, sendo um dos principais objetivos a identificação de obstáculos que possam dificultam o processo educativo. Essa avaliação deve ser feita entre os dois profissionais envolvidos nesse processo. No que diz respeito ao processo pedagógico, a avaliação é realizada para que os professores possam identificar as dificuldades e o rendimento de seus alunos. Ela também avalia o processo, permitindo que seja feito uma análise de todo o sistema de ensino. Segundo Bridi (2011), no campo da educação especial a tipologia de avaliação diagnóstica é significativamente utilizada por professores dos AEE. A avaliação diagnóstica objetiva compreender a maneira pela qual ocorre a produção do conhecimento do educando.

Uma consequência da falta de trabalho em conjunto entre os professores, relativo à realização do parecer pedagógico descritivo do aluno com NEE, é destacada pela P1 do AEE na escola E2: "recebemos os alunos do AEE só depois é feito o parecer e também a sondagem do nível do 
aluno". Nesse caso é feito um relatório individual do aluno com NEE em que os professores preenchem e entregam aos responsáveis ao fim de cada ano letivo. Nessa ficha consta como é o comportamento do aluno, aspectos emocionais, desenvolvimento cognitivo e também suas dificuldades no âmbito da aprendizagem. O método de avaliar não está somente ligado à educação, "verifica-se que a avaliação faz parte da atividade humana de reflexão" (CARMINATTI \&BORGES, 2012, p.165).

Os pareceres descritivos são documentos para avaliar os sujeitos da educação especial que "consistem em uma ficha ou relatório individual, preenchido pelos professores, que é entregue aos pais ou responsáveis pelo aluno no final de cada período letivo (bimestre, trimestre ou semestre) [...]" (SILVA\& FROHLICH, 2011, p.150). A falta de metodologias para fazer a avaliação dos sujeitos da educação especial reflete nas progressões aligeiradas e na desestruturação do sistema inclusivo.

No parecer pedagógico expedido pela professora 1 AEE da El, é exposto os dados pessoais do aluno, a série e turno que frequenta, as atividades desenvolvidas no Atendimento Educacional Especializado, entre elas o ensino de Libras (Língua brasileira de sinais), sistema braile, soroban entre outras atividades. No documento pedagógico de atendimento educacional especializado/2014 do aluno da El, consta uma observação quanto a falta do Relatório do Professor do Ensino Regular. Nesse documento, a professora do AEE relata quais as atividades o aluno mantém maior concentração, ainda "constata-se um grande aprendizado na linguagem de sinais assim também como na escrita que evolui bastante consegue escrever e associar a palavra escrita ao sinal e vice-versa" (PARECER/E1). No parecer pedagógico é descrito todas as cores, os animais, meios de transporte, numerais e frutas que o aluno conhece e reconhece.

Torna-se fundamental discutir nesse momento os efeitos desse parecer na constituição desse sujeito, no caso surdo. Ou seja, segundo o documento, trata-se de um aluno com 14 anos de idade, constituído sob um discurso da falta, da incapacidade cognitiva. Nesse sentido, o parecer 
descreve atividades relativas a um nível de desenvolvimento dispare de um adolescente. Nesse caso, é considerado a infantilização do sujeito e, portanto, a produção discursiva de uma criança e não um adolescente de 14 anos. Segundo o parecer pedagógico descritivo, o aluno apresenta deficiência auditiva, e ainda precisa de vigilância ao "realizar suas atividades de higiene pessoal como tomar banho sozinho, vestir suas roupas, calçar sapatos, escovar os dentes e demonstra total independência na hora da merenda e no momento de ir e vir do banheiro". O documento relata ainda que o aluno adquiriu independência através do trabalho em parceria com a professora de sala de aula regular, professora do AEE e a avó do adolescente.

Embora esteja pontuando um desenvolvimento interativo desse aluno, não direciona essa qualidade ao uso de uma língua própria do surdo, ou de métodos didáticos que envolvam o uso da Língua Brasileira de Sinais e Cultura Surda. Nesse caso a discussão estaria permeada por um outro processo histórico e legal de constituição de sujeitos surdos (LOPES, 2007). O que observamos nesse documento é a constituição de um sujeito da falta da audição e da capacidade linguística.

Com a intenção de pesquisar as relações pedagógicas de professores que atuam na educação especial e professores que atuam na educação inclusiva em sala de aula regular, observamos existir no contexto escolar dois perfis de profissionais. O professor de sala de aula regular parece não se sentir responsável pelo sistema inclusivo, e o professor de $\mathrm{AEE}$, embora apresentem capacitação na área de trabalho, ainda não fica confortável com as relações inclusivas atuais em sua instituição.

\section{CONSIDERAÇÕES FINAIS}

A inclusão ainda tenta se descolar de representações históricas como a de classe especial, reforço, escolas especiais entre outros. Esses registros carregam consigo essas ideias e refletem diretamente nas ações e 
representações profissionais que circulam na escola. E assim, a oferta de uma educação especializada, mesmo que dentro da escola regular sendo transversal a todos os níveis e modalidades de ensino, acaba assumindo o lugar do "estrangeiro", ou do estranhamento naquele espaço, ou ainda, um lugar que marca os sujeitos da falta.

Os educandos assumem a identidade da diferença pela deficiência do corpo e os professores do AEE assumem o posto profissional como únicos responsáveis pelo sistema inclusivo. É uma cadeia discursiva que vai inventando os sujeitos, os lugares e os conceitos sobre a inclusão nesse diferentes contextos de ensino.

É nas representações sociais e consequentemente nos discursos docentes que as pessoas com necessidades educacionais especiais acabam assumindo uma identidade registrada na anormalidade. Essa posição já é lhe dada ao ingressar na escola, quando, no ato da matrícula esse aluno é identificado, categorizado e excluído.

Ainda, os processos avaliativos reforçam essa diferença registrada na deficiência. A avaliação escolar na maioria das vezes é realizada para averiguar se o aluno poderá seguir para a próxima série, e nesse contexto não existe a problematização sobre o tipo de sujeitos que determinadas ferramentas avaliativas vem produzindo, como o próprio parecer pedagógico.

É imprescindível qualificar os profissionais para que a escola possa receber os alunos com necessidades educacionais especiais, não somente matricular esses educandos, é preciso garantir a igualdade de oportunidades. Em uma análise geral, parece que a própria inclusão tenta ser incluída. Os professores de sala de aula regular atribuem ao professor do AEE a responsabilidade pelos "incluídos", por outro lado, o professor de AEE usa o discurso da falta de oferta de formação continuada, mesmo sabendo, na maioria das vezes do investimento público em cursos de formação.

Portanto, o interesse pelo debate do tema, a disposição tanto de acadêmicos na área e docentes colaboradores tem promovido uma 
mobilização que estimula o repensar ações e mudar reações sobre as pessoas com necessidades educacionais especiais. Não há conclusões sobre esse tema. Propõe-se um movimento discursivo para inventar novas representações sobre a educação especial e educação inclusiva, e a partir disso, poder-se, então, falar da possibilidade de um sistema inclusivo eficaz.

\section{REFERÊNCIAS}

BRASIL. Decreto $\mathbf{N}^{\circ} \mathbf{7 . 6 1 1}$, de 17 de novembro de 2011. Dispõe sobre a educação especial e o atendimento educacional especializado.

BRASIL. Diretrizes Nacionais para a Educação Especial na Educação Básica. Brasília: MEC/SEESP,2001.

BRASIL. Política Nacional de Educação Especial na Perspectiva da Educação Inclusiva. Brasília: MEC/SEESP, 2008.

BRASIL. Congresso Nacional. Lei de Diretrizes e Bases da Educação Nacional LDB n. 9.394, de 20 de dezembro de 1996. Diário Oficial da União, 23 de dezembro de 1996.

BRASIL. Constituição da República Federativa do Brasil. Brasília, DF, 5 de outubro de 1988.

BRIDI, F. R. de S. Processos diagnósticos e de identificação dos alunos da educação especial: implicações no contexto escolar. In: THOMA, Adriana da Silva; HILLESHEIM, Betina. (Org.) Políticas de inclusão: gerenciando riscos e governando as diferenças. 1.ed.- Santa Cruz do Sul: EDUNISC,2011. P.70-86.

CARMINATTI, S. S. H.; BORGES, M. K. Perspectivas da avaliação da aprendizagem na contemporaneidade. Est. Aval. Educ.; São Paulo, v.23, n.52, p.160-178, maio/ago.2012

FABRIS, H. E. In/exclusão no currículo escolar: o que fazem com os "Incluídos"?; v. 15, n.1, p.32-39, jan. /abr. 2011

FROHLICH, R.; SILVA, M. L. da. Governando "sujeitos especiais" através dos pareceres descritivos. In: THOMA, Adriana da Silva; HILLESHEIM, Betina. (Org.) Políticas de inclusão: gerenciando riscos e governando as diferenças. 1.ed.Santa Cruz do Sul: EDUNISC, 2011 . p. 145162.

GALLO, S. D.; VEIGA-NETO, A. Ensaio para uma Filosofia da Educação. Educação. São Paulo: Segmento. n.3 (Especial Foucault Pensa a Educação), mar., 2007. p.16-25.

HALL, S. A identidade cultural na pós-modernidade. Rio de Janeiro: DP\&A, 2006.

LOPES, M. C. Surdez e Educação. Belo Horizonte: Autêntica, 2007. 
MAZZOTTA, M. J. da S. Deficiência, educação escolar e necessidades especiais: reflexões sobre inclusão socioeducacional. São Paulo: Editora Mackenzie, 2002.

RECH, T. L. A emergência da inclusão escolar no Brasil. In: THOMA, A. da S.; HILLESHEIM, B. (Org.) Políticas de inclusão: gerenciando riscos e governando as diferenças. 1.ed. Santa Cruz do Sul: EDUNISC,2011. p.19-34.

VEIGA-NETO, A.; LOPES, M. C. Inclusão, exclusão, in/exclusão. Porto Alegre: Verve, 20:121-135, 2011.

Recebido em: Abril de 2016

Aceito em: Julho de 2016 